\title{
NEUROBIOLOGÍA DEL DESARROLLO TEMPRANO
}

\author{
Dra. María Luisa Poch Olivé \\ Neuropediatra, Hospital San Millán, Logroño
}

\begin{abstract}
RESUMEN. Se describe el desarrollo del sistema nervioso humano desde las etapas embrionaria y fetal hasta los primeros años de vida, lo que se ha venido a llamar neurobiología del desarrollo temprano. Se contemplan tanto los aspectos estructurales como los funcionales, los cambios que se producen y los factores genéticos y epigenéticos que influyen en dichos cambios.

En la primera parte se describe la formación del sistema nervioso, la proliferación, organización y maduración neuronal añadiendo a los conocimientos "clásicos" las aportaciones recientes de la genética y la citoarquitectura cerebral. También se revisan los conceptos actuales de plasticidad cerebral y la especialización por áreas como base biológica de los aprendizajes.
\end{abstract}

ABSTRACT. This paper describes the development of human nervous system from the embryonic and fetal phases to the first years of life, period called early developmental neurobiology. You can find the structural and functional aspects, the changes produced and the genetic and epigenetic factors that have influence in these changes.

In the first part it is described the construction of the nervous system, the neural proliferation, organization and ripening, adding to the "classic" knowledge the new contributions of the genetics and the brain citoarchitecture. The paper also revises the recent concepts about the cerebral plasticity and the specialization in areas as the biological basis of learning.

El sistema nervioso es el soporte material para el conocimiento, la afectividad y la conducta. La neurobiología lo estudia desde el punto de vista de su maduración, es decir, de su estructuración como órgano, proceso que lleva inherente los cambios anatómicos, la genética y la capacidad de integrar funciones por parte de dichas estructuras gracias al aprendizaje.

En las primeras etapas lo que domina es la estructura recibida, pero posteriormente, más pronto de lo que pensamos, el aprendizaje va a modificar el complejísimo sistema nervioso orgánico: el cerebro es un procesador de información "in vivo" que se modifica y se remodela a partir de los programas genéticos y de las aferencias experienciales. Por lo menos tres fuerzas están trabajando constantemente: la maduración del sistema nervioso, la competencia del niño desde su periodo fetal y la interacción con el ambiente (Johnson,1997; Parker, 2000).

En cuanto a la maduración del sistema nervioso, clásicamente se describen los cambios anatómicos e histológicos del sistema nervioso en lo que se denomina la morfogénesis descriptiva (Langman, 1969; Dobbing y Sands, 1973; Volpe, 1980), pero 
los conocimientos recientes de genética y bioquímica molecular han dado lugar a una comprensión más profunda de estos cambios y por qué se producen con una secuencia temporal y espacial tan bien programada (Marín Padilla, 1991; Sarnat 1992,1998; Anderson, 1995; Rubenstein, 1998).

La embriología clásica describe las etapas del desarrollo orgánico del sistema nervioso a partir del ectodermo del embrión por medio de mecanismos de inducción dorsal y ventral, lo que es conocido como neurulización. De la misma capa ectodérmica deriva la piel y todas las estructuras sensitivas. La capa que está por debajo, en íntima relación con el ectodermo, es el mesodermo, de ella derivan las estructuras óseas y musculares en relación con el sistema nervioso. Una vez finalizado el proceso de neurulización el sistema nervioso sufre una fase de proliferación en la que existe un aumento de células que posteriormente irán a ocupar su lugar, fase de migración, para, una vez instaladas, organizarse y establecer conexiones entre ellas, lo que se conoce como fase de organización. Posteriormente el sistema nervioso se enriquece y mejora su función por medio de la mielinización.

La nueva neuroembriología es una síntesis integrada de los cambios anatómicos y los programas genéticos que rigen la diferenciación, lo que en un futuro posiblemente permitirá prevenir, e incluso tratar, trastornos del sistema nervioso. Los avances en bioquímica también han permitido conocer la maduración funcional del sistema nervioso y cómo pueden influir los factores epigenéticos (experiencias, nutrición, tóxicos...), lo cual es muy importante para prevenir y tratar algunos trastornos del sistema nervioso.

\section{Neurobiología del desarrollo}

\subsection{Periodo de inducción}

Hay una inducción dorsal y otra ventral que se inician entre la tercera y cuarta semanas de gestación y termina en la sexta semana con la formación del tubo neural, se llama también periodo de neurulización. Posteriormente este tubo se vesiculiza y segmenta para dar lugar a las diferentes partes del sistema nervioso central. Las alteraciones en este periodo son muy importantes, algunas incompatibles con la vida como la anencefalia (ausencia de encéfalo), otras, compatibles con la vida, como el mielomeningocele (falta de cierre de los arcos posteriores con herniación de la médula) que origina una alteración funcional grave.

La creación y desarrollo del tubo neural puede definirse en términos de gradientes de influencias inductivas: la inducción es un término que indica la influencia de un tejido embrionario sobre otro, de manera que los dos, el inductor y el inducido, se diferencian para formar tejidos muy distintos. La inducción puede ocurrir entre dos capas germinativas diferentes, la inducción de la placa neural (ectodérmica) por la notocorda (mesodérmica) o, en ocasiones, en una sola capa germitativa como por ejemplo, la cúpula óptica (neuroectodérmica) que induce la formación del cristalino y de la córnea (ectodérmica). En el caso de la córnea si no existiera esta inducción sólo sería epidermis.

El proceso de inducción fue descubierto en 1924 (Spemann y Mangold) demostrando que el labio dorsal de la salamandra poseía la capacidad de causar la formación de un segundo sistema nervioso si era trasplantado a otro sitio en un 

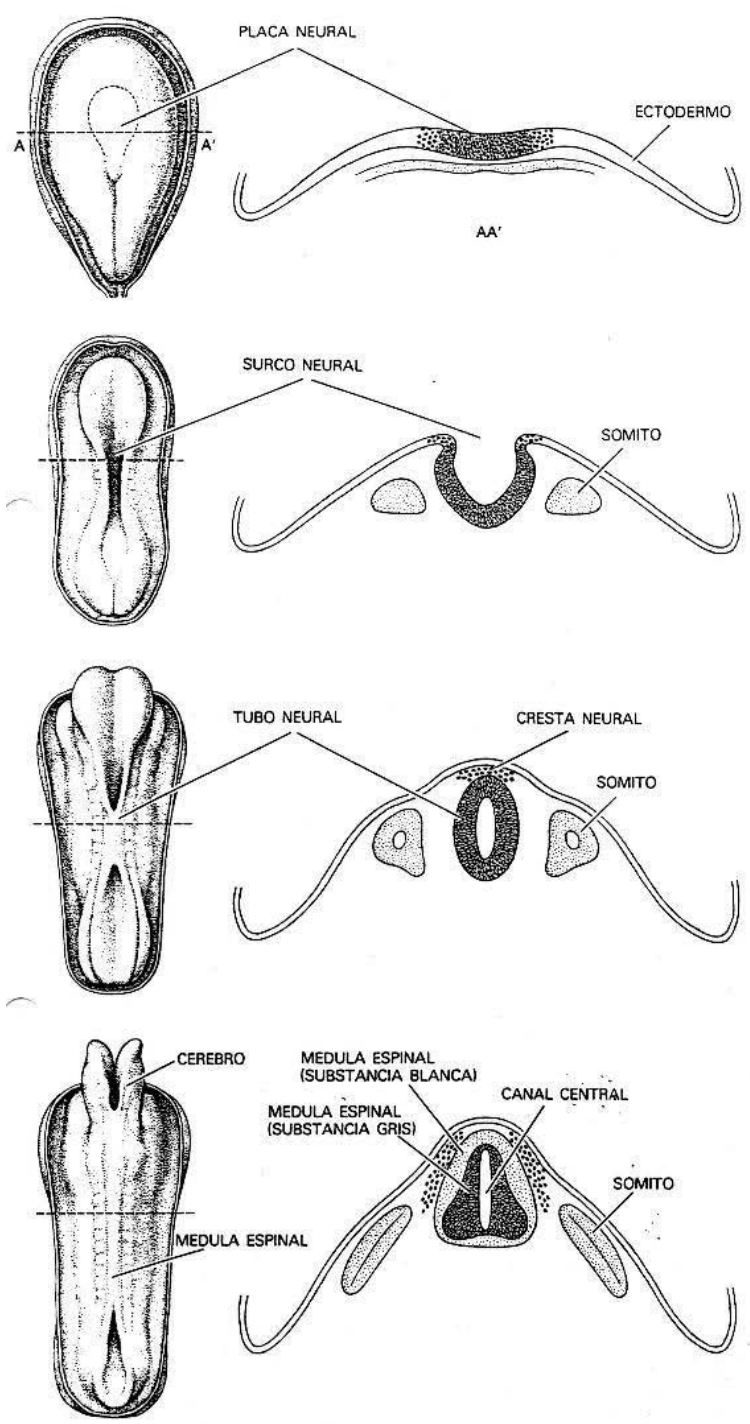

Figura 1: Génesis del sistema nervioso a partir del ectodermo o capa celular externa, de un embrión humano a partir de la tercera o cuarta semana después de la concepción esbozada en estas cuatro parejas de dibujos, que representan una visión externa del embrión en desarrollo (izda.) y una visión de la sección transversal correspondiente hecha aproximadamente a la mitad de la futura médula espinal (dcha.). El sistema nervioso central empieza con la placa neural, una lámina plana de células ectodérmicas situadas en la superficie dorsal del embrión. La placa se pliega dando una estructura hueca Ilamada tubo neural. El extremo cefálico del canal central se ensancha para formar los ventrículos. El sistema nervioso periférico deriva en gran parte de las células de la cresta neural y de fibras nerviosas motoras que salen de la parte inferior del cerebro a nivel de cada segmento de la futura médula espinal. Extraído del artículo de Cowan,WM. (1987) Desarrollo del cerebro. Investigación y Ciencia, 68- 82. 
embrión receptor de la misma especie. El gen regulador con acción principal sobre el nódulo primitivo, la notocorda y la placa neural es conocido como gen Cnot (Stein, 1995). La especificidad de la inducción no es la molécula inducida sino los receptores de membrana de la célula inducida, esto es importante porque moléculas parecidas pueden ser reconocidas por el receptor de membrana como iguales y pueden desempeñar un papel teratógeno. La especificidad de la membrana receptora está también genéticamente programada, un gen llamado Notch tiene especial importancia en regular la competencia de una célula a reaccionar ante las señales inductoras (Fortini, 1993).

Algunos tejidos mesodérmicos como el músculo liso del intestino fetal, pueden servir de inductores para el neuroepitelio al aumentar la proliferación celular, pero este fenómeno no es la inducción verdadera pues las células que han proliferado no se diferencian y no maduran.

Este concepto es importante en la inducción: la competencia de la célula inducida, es decir, la inducción tiene lugar en una época muy precisa y limitada, este periodo de respuesta de la célula es lo que se denomina competencia. La misma célula no va a poder responder ni antes ni después de este periodo.

Una vez formado el tubo neural se produce una diferenciación en tres dimensiones: longitudinal, circunferencial o coronal y radial, que va segmentando en compartimentos que forman una verdadera barrera física y química. La parte más caudal da lugar a la médula espinal que está a su vez segmentada debido a la agrupación de las raices y nervios periféricos, impuesta por la segmentación del mesodermo circundante que forma las vértebras y estructuras asociadas. El segmento siguiente va a dar lugar al tallo cerebral y tiene a su vez ocho segmentaciones que originan el cerebelo y las diferentes partes del tronco cerebral. La parte más cefálica da lugar a las distintas partes del encéfalo hasta llegar a los hemisferios cerebrales.

La dimensión coronal del tubo neural es crítica pues distingue entre la zona dorsal, correspondiente a procesos sensoriales, y la zona ventral, que se corresponde con procesos motores. Los procesos que siguen a la neurulización se realizan fundamentalmente en el plano radial.

\subsection{Periodo de proliferación}

Entre el segundo y cuarto mes de gestación se produce un marcado aumento del número de células formando una gruesa capa en la zona más profunda del tubo neural, Ilamada zona ependimaria o subventricular. Alteraciones en esta etapa producen una microcefalia vera, es decir, cerebro pequeño por escasez celular. Este tipo de microcefalia es diferente del que se produce en la fase de organización en que la muerte de células o la desaparición de conexiones neuronales pueden dar lugar a microcefalia. Otras microcefalias se producen por actuación de un daño isquémico, es decir, una falta de aporte de sangre y oxígeno a un cerebro que tiene una celularidad normal (microcefalias encefaloclásticas).

En todas las especies de mamíferos se producen millones de neuronas, las estimaciones suponen que el cerebro humano adulto posee entre 300.000 a 1.000 .000 de millones de células, pero las que se produjeron en la fase de proliferación fueron millones más. Las zonas de proliferación están en lo más profundo del tubo neural, allí proliferan las neuronas y las células gliales por división repetida de células "clones" que tienen un único precursor celular: los neuroblastos dan lugar a las neuronas 


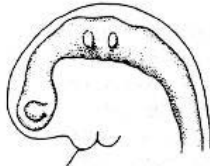

25 DIAS

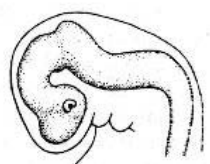

35 DIAS

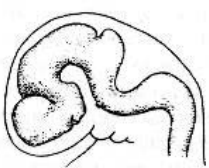

40 DIAS

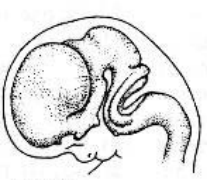

50 DIAS

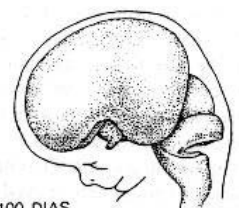

100 DIAS

สา

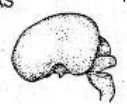

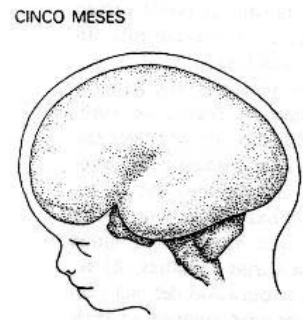
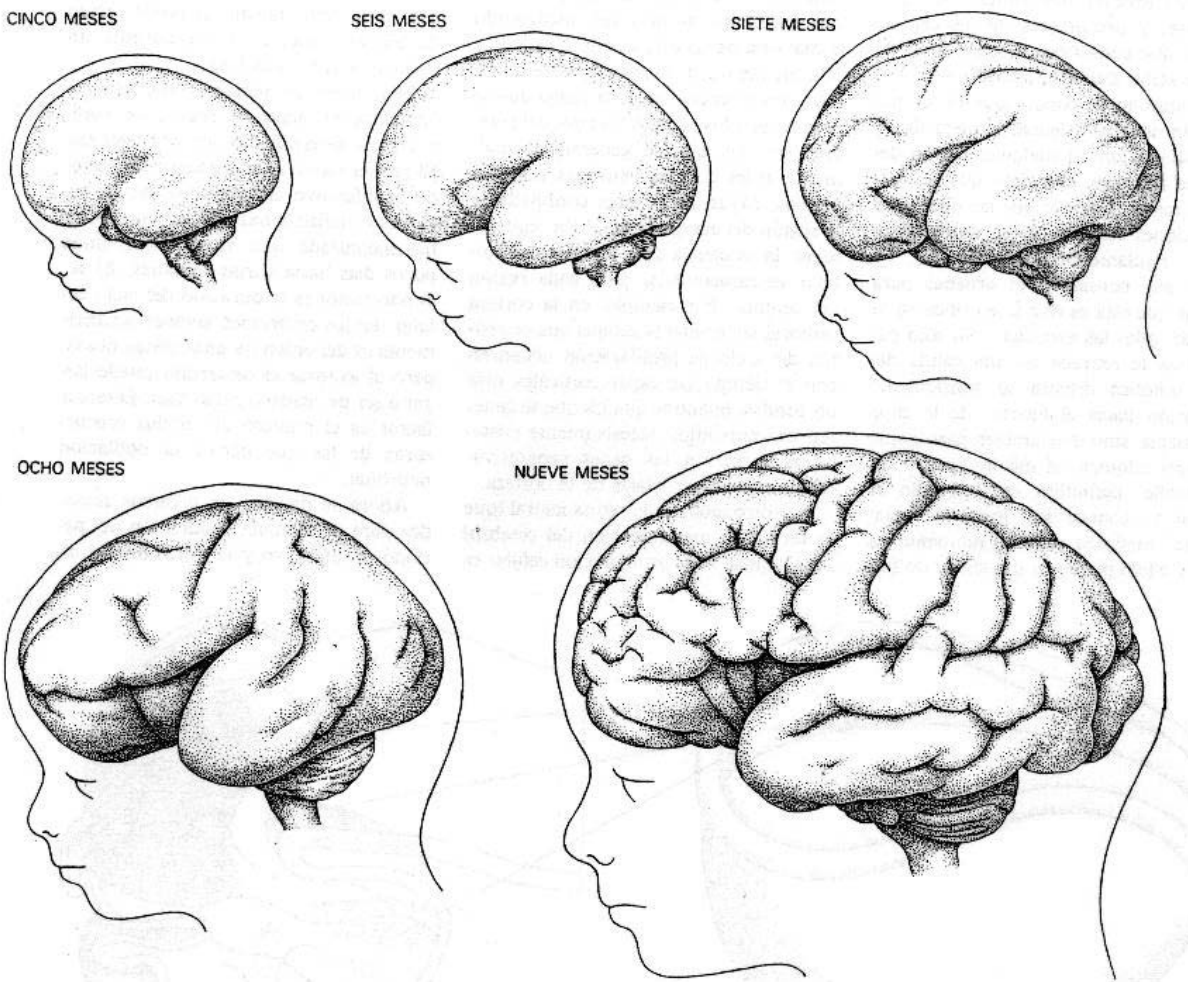

Figura 2: Visión lateral del cerebro que en esta secuencia de dibujos muestra una sucesión de fases embrionarias y fetales. Los dibujos de la secuencia principal (abajo) están todos reproducidos a la misma escala: aproximadamente cuatro quintos del tamaño en vivo. Los cinco primeros estadios están aumentados a un tamaño común arbitrario con el fin de clarificar sus detalles estructurales (arriba). Las tres partes principales del cerebro (anterior, medio y posterior) se originan a modo de abultamientos prominentes en el extremo cefálico del joven tubo neural. En los seres humanos los hemisferios cerebrales terminan por crecer por encima del cerebro medio y del cerebro posterior, y también cubren parcialmente el cerebro. Las circunvoluciones e invaginaciones de la superficie del cerebro aparecen hacia la mitad del embarazo. Considerando que el cerebro humano desarrollado contiene del orden de cien mil millones de neuronas y que prácticamente no se añaden neuronas después del nacimiento, puede calcularse que las neuronas deben generarse en el cerebro a un ritmo promedio de más de 250.000/min. Extraído del artículo de Cowan, WM. (1987) Desarrollo del cerebro. Investigación y Ciencia, 68- 82. 
y los glioblastos a las células gliales. La proliferación tiene lugar a "paso ligero", después de pasar por varios ciclos de división celular ésta se detiene. Aunque se desconoce lo que pone en marcha y detiene el mecanismo de proliferación en cualquier región está claro que los momentos en que ocurre están rígidamente determinados, es una fase crítica de crecimiento cerebral. Este mecanismo parece que dura toda la vida, aunque es más acentuado en esta fase embrionaria. En roedores se conocen dos áreas donde la neurogénesis se mantiene activa hasta edades muy avanzadas, la zona subventricular y la del giro dentado del hipocampo. Varios factores parecen jugar un papel de control de estos procesos, por ejemplo el ácido retinoico y la adenosina monofosfato cíclico (AMPc) la facilitan; por otra parte la deplección de serotonina la reduce y lo mismo ocurre cuando hay deficiencia de hormona tiroidea (Palmer 1997, Brezun 1999, Bergado-Rosado 2000).

La secuencia de la proliferación celular es característica para cada región del cerebro, por ejemplo, las que empiezan pronto son las que ocupan los lugares más profundos de las capas corticales, mientras que, las que empiezan más tarde son las que forman las capas más superficiales.

Parece existir un reloj celular que indica el inicio y el final de la proliferación. En el momento en que la neurona deja de sufrir mitosis, es decir, pierde su capacidad de síntesis de ADN, se dice que es su "fecha de nacimiento", ésta va a influir en el sitio que esta neurona ocupe definitivamente y se cree que también en la pauta de conexiones que va a establecer. En experimentos en los que se administran pequeñas cantidades de timidina marcada a los embriones, se conocen las "fechas de nacimiento" de las células de muchas partes del cerebro para distintas especies (Cowan 1987).

\subsection{Periodo de migración}

Ocurre durante el segundo trimestre de gestación, millones de células emigran desde su situación periventricular hasta el lugar asignado, hay migración radial y tangencial, todo el proceso está genéticamente controlado. Las alteraciones en este periodo son variadas, todas producen graves consecuencias en el desarrollo posterior. En términos anatomopatológicos se habla de poligiria (número de giros y surcos aumentado), polimicrogiria (giros y surcos aumentados en número pero pequeños de tamaño), heterotopias neuronales (neuronas fuera del lugar que les pertenece), etc.

Algunas neuronas han de recorrer un camino larguísimo, lo hacen trepando por los brazos de unas células gliales que sirven de guías, es una forma altamente especializada de locomoción celular dependiente de las relaciones entre neurona y glía a través de unos cortos filopodios (especie de pies emitidos por la neurona) que, franqueando el espacio interneural, se insertan en la guía. Los estudios moleculares de este proceso migratorio se centran sobre la presencia de una proteína, la astrotactina, que funciona como un señalizador de primer orden. Terminada la migración, las neuronas se independizan de las guías y quedan bajo la influencia de otros factores quimiotácticos de adhesión celular para ordenarse en las diversas capas que constituyen la corteza cerebral y cerebelosa. Todos estos procesos están regulados genéticamente (Dobbing y Sands 1973, Volpe 1980, Rakic 1988, Marín Padilla 1992).

Todas las neuronas piramidales Ilegan a la capa más superficial, que está formada por un entramado de neuronas con grandes expansiones, y luego ocupan su posición en la capa cortical correspondiente. Las primeras neuronas ocupan los estratos más bajos y las siguientes van colocándose progresivamente por encima de las preceden- 
tes. La migración se produce desde abajo hacia arriba porque todas las neuronas deben alcanzar obligatoriamente la capa I y establecer los contactos funcionales con sus componentes (Marín Padilla 1992,1998,2000). La migración neuronal y la formación ascendente preceden a la diferenciación específica de las neuronas, hay una fase temprana controlada por las células de Cajal-Retzius de la capa 1 de la corteza cerebral y la secreción de sustancias químicas, entre ellas la más conocida es la reelina. La segunda fase viene controlada por el tálamo y comprende la diferenciación ascendente, específica y fenotípica de las neuronas (Johnson, 1997; Marín Padilla,1992, 2000; Ogawa, 1995; Del Río, 1997) .

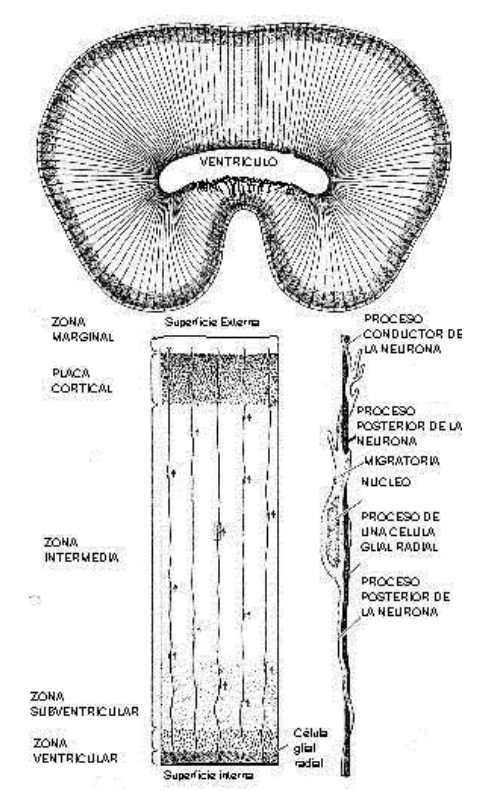

Figura 3: Las células especializadas de sostén, las células gliales radiales, se forman durante los estadios precoces del desarrollo del sistema nervioso. Estas células se distinguen por sus procesos extremadamente largos, que atraviesan todo el espesor de la pared del tubo neural y sus estructuras derivadas. El dibujo de la parte superior muestra el aspecto de las células gliales radiales en una preparación teñida por el método de Golgi de una sección transversal gruesa de la pared del hemisferio cerebral de un feto de mono. Los cuerpos celulares están en la zona ventricular y sus procesos se extienden hasta la superficie externa de las capas circundantes, donde parece que formen uniones terminales expandidas. En la parte inferior izquierda se muestra una ampliación de un segmento de esta sección transversal. La pequeña porción de tejido comprendida dentro del rectángulo puede verse a más aumento en la imagen tridimensional detallada en la parte inferior derecha, basada en los estudios microscópicos de Rakic. Esta ilustración revela la estrecha relación existente entre los procesos de las células gliales radiales y las neuronas migratorias, relación que se observa en el desarrollo de la mayoría de partes del cerebro (llustración realizada por Tom Prentiss. Extraído del artículo de Cowan,WM. (1987) Desarrollo del cerebro. Investigación y Ciencia, 68-82. 
Es muy importante el contacto que establece la neurona con la capa 1, desde allí queda una conexión anclada desde el principio del desarrollo que es crucial para la citoarquitectura de la corteza. Las neuronas que retienen su contacto con la capa 1 se diferencian en células piramidales, mientras que, las que dejan su anclaje, quedan libres para desarrollar distintos tipos de neuronas que asumen una función inhibidora (Marín Padilla, 1992,2000). Existe un 30\% de células inhibidoras de las grandes células piramidales que se desarrollan y maduran sin el anclaje a la capa I. Estas neuronas parece que son las reponsables de procesos motores finos, coordinación y modulación del movimiento, y se cree que son las que se alteran en muchos problemas de aprendizaje. Las piramidales son responsables de procesos motores más globales y su alteración produce las parálisis y alteraciones del movimiento y postura.

Existe también una migración horizontal, menos conocida y de menor volumen, pero no por ello de menor importancia. No existe migración longitudinal a lo largo del tubo neural ya que cuando se forman los distintos segmentos de médula, tronco y encéfalo, existen unas barreras físicas formadas por prolongaciones de las células gliales y barreras químicas que repelen las células migratorias, lo que impide una migración longitudinal.

Hay una zona donde las células de la zona ventricular migran y siguen proliferando en la zona subventricular, esta capa da lugar a estructuras profundas del hemisferio cerebral, los Ilamados ganglios basales, que tienen importante relación con la corteza cerebral.

\subsection{Organización}

Se inicia a los seis meses de gestación y se prolonga durante los primeros años de vida. En el último trimestre de gestación y durante los dos primeros años de vida el ritmo de organización es acelerado, luego se hace menos rápido hasta los diez años de vida aproximadamente para proseguir de forma pausada durante toda la vida. Se produce durante este periodo un gran aumento del número de prolongaciones de las neuronas (dendritas) y sus pequeñas ramificaciones, lo que se ha venido a llamar arborización dendrítica, se forman numerosas conexiones entre las terminaciones nerviosas (sinapsis), todas las células y sus prolongaciones se disponen en capas y se orientan (citoarquitectura), se produce también la muerte celular programada (apoptosis), la diferenciación y especialización celular. Estos procesos se producen bajo la influencia de factores neurotróficos y de su interacción con influjos aferentes. Son conocidos los factores de crecimiento cerebral y las moléculas de adhesión neuronal, muchos de ellos codificados por genes (ecan, tag-1, etc.). (Cowan, 1984; Janowsky, 1986; Huttenlocher, 1990,1994; Marín Padilla 1992, 2000).

Durante el desarrollo en la última etapa del embarazo y en el periodo postnatal existe una fase aditiva de superproducción de sinapsis y fibras, incluyendo su mielinización posterior, seguida de una fase regresiva de eliminación sináptica. Además de aumentar el número las conexiones sinápticas se van especializando. Esta fase de expansión neuronal, Ilamada hodogénesis (formación de los caminos) se realiza por medio del crecimiento de las prolongaciones neuronales en busca de dianas para establecer sus conexiones. En general se produce a ritmo muy acelerado en el tercer trimestre de gestación y durante los 2 primeros años de vida para ser más lento durante los 10 primeros años y llegar al ritmo del adulto a partir de entonces. El proceso existe siempre, por eso aprendemos siempre pero con más dificultad a medida que 
crecemos y nuestras neuronas se especializan. El axón va buscando el camino por medio del cono de crecimiento que tiene unas expansiones que se denominan filopodia que siguen señales químicas. Diversos factores de crecimiento neuronal juegan un papel importante en este camino que acaba cuando se llega a la célula diana. La aposición de axones se realiza gracias a moléculas de adhesión neuronal que ejercen un efecto de quimioafinidad, se llaman adhesinas, integrinas, inmunoglobulinas... Cada axón encuentra su camino determinado donde tiene que contactar con la célula diana (Marín Padilla, 1992; Huttenlocher, 1990,1994; Sarnat,1998; Bergado,2000).

El gradiente de ramificación dendrítica depende de la complejidad funcional de cada sistema y de su interacción con los estímulos del entorno. Durante la fase aditiva el aumento más intenso se da alrededor del nacimiento con picos de densidad a diferentes edades según las diferentes zonas, por ejemplo, en la zona del córtex visual hay un rápido aumento a los 3 ó 4 meses postnatales y la máxima densidad (un $150 \%$ del adulto) hacia el año de vida; algo parecido ocurre con el córtex auditivo. Por el contrario, en las zonas prefrontales el inicio es a la misma edad pero el pico máximo se alcanza tras el primer año (Huttenlocher 1990, 1994).

En la fase regresiva existe una pérdida selectiva de sinapsis que se produce tras los periodos de gran intensidad. Al igual que los picos de formación de sinapsis, el tiempo de reducción varía de unas regiones a otras, por ejemplo, la densidad sináptica de la corteza visual disminuye a niveles de adulto entre los 2 y los 4 años mientras que en la corteza prefrontal ocurre entre los 10 y los 20 años (Cowan, 1984; Janowsky, 1986).

Todos estos fenómenos son la base de la Ilamada plasticidad cerebral.

Los trastornos graves en este periodo dan lugar a una afectación severa del desarrollo. Son más frecuentes los trastornos concomitantes, por ejemplo debidos a una infección intraútero, una cromosomopatía, un déficit nutricional, etc. En el caso de algunas alteraciones cromosómicas las espinas dendríticas son menores en número y tienen menor tamaño, por ejemplo en la trisomía 21, en el caso de la fragilidad del cromosoma $X$ existen menor número de sinapsis establecidas y la neurotransmisión está disminuida. En el caso de hipotiroidismo existen alteraciones de todos los procesos de proliferación y organización.

\subsection{Fase de mielinización}

Este proceso acompaña a la organización, se inicia en el tercer trimestre y dura varios años. La mielina es una sustancia que permite que la conducción nerviosa sea más rápida y perfecta. Se produce por los oligodendrocitos, que son células gliales, que se enrollan en torno al axón y se van cargando de sustancias proteo-lipídicas (el colesterol es un marcador de la mielinización).

En el sistema nervioso periférico mielinizan antes las vías motoras que las sensoriales, en el sistema nervioso central ocurre al contrario, esto explica que el niño sea capaz de oir y ver mucho antes que gatear o andar y que no se puedan alterar las etapas del desarrollo, que siguen siempre una misma secuencia cefalocaudal y desde segmentos proximales a distales. Las áreas de asociación son las más tardías en mielinizarse y continuan el proceso durante la segunda década de la vida. La mielinización se inicia en momentos distintos y posee un ritmo y duración variables para cada región del sistema nervioso (Yacovlev, 1967; Gilles, 1983).

Además de factores genéticos los factores nutricionales parecen ser importantes en este proceso. Existen causas comunes que producen trastornos de la organiza- 
ción y la mielinización como son las infecciones intraútero, la desnutrición, tóxicos o drogas, las alteraciones cromosómicas, las infecciones del sistema nervioso post-natales, etc. En ocasiones la alteración de la mielina se produce por factores genéticos, las Ilamadas enfermedades desmielinizantes, en las que se altera la formación de la mielina.

De modo paralelo a los procesos de organización y mielinización, que tienen su máxima intensidad durante el tercer trimestre de embarazo y los dos primeros años de vida, se produce un aumento de tamaño del sistema nervioso: el cerebro del recién nacido pesa unos 330 grs., se duplica a los 8 meses ( 700 grs.) y se triplica a los 18 meses (1100grs.). Desde esa fecha hasta la edad adulta sólo va a ganar 400 gramos más. Desde el punto de vista bioquímico el aumento del número de células se traduce en un rápido aumento de ácido desoxirribonucleico (DNA) y la mielinización en un aumento del colesterol (Gilles, 1983).

\subsection{La irrigación}

La formación de los vasos que van a irrigar el sistema nervioso en formación también cambia a lo largo del crecimiento, la diferente distribución y ramificación de las arterias va siguiendo los cambios anatómicos y la aparición de circunvoluciones.

A las 15 semanas de gestación los vasos se están "acumulando" en la superficie cerebral, cada décima de milímetro hay un perforante en un cerebro que pesa 10 gramos. A las 20 semanas se ven abundantes vasos perforantes en la superficie, también cada décima de milímetro, lo que se mantiene constante hasta la edad adulta en la que el cerebro ha aumentando 1000 veces su tamaño (Marín Padilla 2000).

La distribución y unión (anastomosis) de los vasos de superficie va cambiando con la aprición de los surcos y circunvoluciones cerebrales. En un principio los vasos se forman en la parte más externa, son los plexos meníngeos que forman como un manto que cubre íntimamente la superficie del cerebro. En este plexo meníngeo se originan los vasos perforantes que penetran en la corteza cerebral por medio de unos "pies" (filopodios) que van entrando en la sustancia gris (Marín Padilla, 2000).

En la zona ventricular también se originan vasos que van penetrando desde lo más profundo. Quedan unas zonas muy sensibles a la falta de riego, como se puede apreciar en arteriografías realizadas en cerebros de niños prematuros y de niños a término. En el cerebro del niño nacido prematuro la zona que más sufre la irrigación insuficiente es la zona límite entre los vasos internos y los externos. La lesión típica que se produce en el prematuro es en la zona periventricular y la zona correspondiente a la sustancia blanca. Se podría pensar que esta lesión no es tan importante como la que afecta a la corteza donde están las neuronas, pero no es así, la sustancia blanca queda "desconectada" y se producen alteraciones como la parálisis cerebral infantil o la epilepsía. Otro tipo de lesión que ocurre por falta de irrigación es la isquemia de un territorio dependiente de una gran arteria cerebral que produce un daño en una zona determinada, como por ejemplo, la zona del córtex motor unilateral, la manifestación clínica es una parálisis de un hemicuerpo.

\subsection{Los neurotransmisores}

En los últimos años se ha progresado en la identificación de las distintas sustancias trasnmisoras, en la determinación de las áreas cerebrales y en el esclarecimiento de 
los acontecimientos moleculares de la transmisión sináptica. Además de identificar la estructura molecular de los neurotransmisores y su distribución anatómica se ha avanzado también en los acontecimientos bioquímico- moleculares de la transmisión sináptica. Estas sustancias transmisoras se clasifican en intrísecas (originadas en el córtex cerebral) y extrínsecas (originadas fuera del córtex). Existen muchísimas sustancias que actúan como transmisoras, las más conocidas y caracterizadas son el glutamato, el ácido gamma-amino-butírico (GABA), la acetilcolina, la normadrenalina, la serotonina, la dopamina, etc.

Las cantidades de estas sustancias varían a lo largo del desarrollo, por ejemplo, el glutamato, que juega un papel importante en la excitación de las células piramidales, se ha observado que en ratas de 10 a 15 días aumenta rápidamente en cantidad para llegar a un pico de 10 veces el nivel de la rata adulta, para posteriormente descender hacia el día 25 de forma drástica. El GABA es un importante inhibidor intrínseco en el cerebro de los mamíferos, se ha podido medir un gran aumento de densidad de los receptores GABA en el periodo perinatal y en las 3 primeras semanas en los cerebros de gatos, parece que estos niveles están influidos por experiencias sensoriales (Fosse, 1989).

La acetilcolina, originada en los ganglios basales, muestra niveles de adulto humano a los 10 días de vida. La noradrenalina, que se asocia a la plasticidad cortical, se encuentra en grandes cantidades en el recién nacido (Benes, 1994). La serotonina y la dopamina tienen un comportamiento similar, aumentan rápidamente en los últimos meses prenatales y primeros meses postnatales (Johnston, 1988).

\section{Citoarquitectura cerebral, función, especialización}

Existe un debate, todavía no resuelto, en cuanto a la pre-especificidad de la estructura y la función neuronal como resultado de la interacción molecular y celular antes de los efectos de la experiencia. La corteza cerebral se diferencia en áreas por su estructura laminar aunque es difícil y controvertido marcar los límites entre regiones. En general se cree que las áreas anatómicas distintas lo son también funcionalmente, algo que se puede observar entre áreas sensoriales o motóricas, sin embargo, en otras áreas esta división no está tan clara. Parece ser que, mientras la arquitectura básica (tipo y número de células, circuitos) es innata, los patrones de conexiones entre las células (dendritas, sinapsis) dependen más de la experiencia (Johnson, 1997).

Los patrones de migración descritos por Rakic (1988) explican cómo cada célula ocupa su lugar pero no pueden explicar cómo se realiza la diferenciación en distintas capas. Existe la opinión de que la neurona se diferencia antes de ocupar su definitivo lugar, experiencias con ratones mutantes "reeler" apoyan esta idea al observar que las células que migran a posiciones equivocadas del córtex se diferencian en tipos de neuronas de acuerdo al momento en que fueron originadas, esto implica que la información requerida para la diferenciación está presente cuando la célula nace en la zona proliferativa ventricular.

La nueva teoría de la arquitectura de la neocorteza, desarrollada por Marín Padilla $(1992,1998,2000)$ propone que la placa piramidal de la corteza se estratifica progresivamente y que el número de estratos piramidales ha ido en aumento desde el erizo hasta el hombre. El desarrollo prenatal de la placa piramidal en una fase temprana coincide con la migración neuronal y culmina con la formación de 
la capa 1, todas las células de la capa piramidal quedan ancladas de la capa 1 y se van colocando de abajo a arriba por orden de llegada en la llamada placa piramidal, esta fase es común a todos los mamíferos. En la fase tardía hay una diferenciación funcional ascendente de las neuronas de la placa piramidal. En el humano la fase se inicia alrededor de la decimoquinta semana de gestación, continúa durante el periodo del nacimiento y durante el periodo postnatal, posiblemente dura toda la vida. La diferenciación funcional de las neuronas prosigue de abajo a arriba y acompaña a la penetración de fibras que provienen del tálamo que influyen en la diferenciación funcional.

Molnar y Blakemore (1991) han investigado las influencias del tálamo sobre la capa 4 de la corteza a partir de piezas de tálamo y de corteza visual puestos en cultivo en una placa de Petri, observando que las aferencias del tálamo no sólo llegan al córtex visual a un tiempo determinado sino que, además quedan en la capa adecuada (capa 4) seguramente por influencias moleculares. Estos investigadores han realizado la misma experiencia con corteza de otras áreas y cerebelo, observan que las aferencias nunca penetran en el cerebelo, pero sí en el hipocampo, sugieren que existen unas sustancias que permitirían esa invasión y las denominan "growth permitting substrate" (sustrato que permite el crecimiento).

Surgen así dos teorías : según el esquema de Rakic (1988) existe un protomapa de las células en la capa germinal, de forma que están pre-especificadas y migran a las áreas particulares. Es una idea atractiva pero difícil de defender en contra de la evidencia de que la corteza es relativamente equipotencial y plástica en los primeros años. La segunda teoría es el protocórtex, según la cual las diferentes áreas corticales provienen de un protocórtex indiferenciado que se especializa como resultado de las proyecciones del tálamo (O'Leary, 1989; Killackey,1990).

Johnson (1997) en un esfuerzo de sintetizar estas ideas comenta la existencia de influencias e interacciones entre células y moléculas que influyen en muchos aspectos de la estructura laminar del córtex y sus patrones de conexión, muchas células están diferenciadas antes de llegar a su destino, lo que no significa que las células de un área particular estén pre-especificadas para procesar un determinado tipo de información. La diferenciación en áreas está influida por las proyecciones del tálamo y la secuencia temportal de crecimiento neural.

Otras estructuras cerebrales no corticales como el hipocampo, el cerebelo y el tálamo se desarrollan antes del nacimiento y se reorganizan en la vida postnatal. El sistema límbico está diferenciado a las 18-19 semanas de gestación, las grandes circunvoluciones no empiezan a emerger hasta las 24-31 semanas, la neurogénesis del cerebelo se inicia en el primer trimestre de gestación y continúa tras el nacimiento (Spreen, 1995). La neurobiología de estas estructuras es menos conocida pero se tiene constancia de la importancia de su desarrollo para los procesos cognitivos tempranos.

\section{Conceptos neurobiológicos}

\section{Plasticidad}

Existe una remodelación continua de la organización y maduración neuronal, capacidad que se va haciendo menor a medida que las células se van especializando. Es una cualidad común de los organismos vivos que permite la adaptación del 
sujeto a las circunstancias que alteran el programa genético, enriqueciéndolo o bien disminuyendo las consecuencias negativas de alguna lesión ocurrida en un sistema nervioso bien estructurado.

Durante muchos años se consideró al sistema nervioso como una estructura funcionalmente inmutable y anatómicamente estática, existen numerosas experiencias que demuestran que el sistema nervioso es un producto nunca terminado, continuamente influido por la interacción de factores genéticos y epigenéticos.

Los mecanismos de neuroplasticidad son múltiples, desde modificaciones morfológicas extensas como la regeneración de axones, la formación de nuevas sinapsis, hasta sutiles cambios moleculares que alteran la respuesta a las sustancias transmisoras.

\section{Diferenciación y especialización}

Las sinapsis aumentan en número en una primera fase de redundancia transitoria, se van especializando, algunas son eliminadas y otras, las especializadas, llegan a una estabilización sináptica selectiva.

\section{Apoptosis o muerte celular programada}

En el periodo de proliferación y organización hay un aumento marcado de neuroblastos, el $40 \%$ de ellos desaparecen, esta muerte celular está genéticamente programada. Durante el desarrollo cerebral existe una fase de superproducción de sinapsis, redundantes, seguida de una fase regresiva de eliminación sináptica que está controlada genéticamente.

Es diferente de la muerte celular que ocurre en procesos destructivos que provocan la deplección neuronal suplementaria. Una alteración entre el balance de producción y de muerte neuronal puede dar lugar a microcefalias y atrofias cerebrales en el caso del cerebro o a alteraciones en la función medular, como por ejemplo las atrofias espinales congénitas, en las que falta el gen que controla el fin de periodo de muerte celular programada de las neuronas medulares.

\section{Genes reguladores y genes organizadores}

El desarrollo temprano del sistema nervioso central, ya desde el momento de la formación de la placa y el tubo neural, requiere el establecimiento de un plan fundamental del cuerpo para la simetría bilateral, la identificación de la parte cefálica y la caudal y de las superficies ventral y dorsal. Los genes que determinan estas polaridades y gradientes anatómicos se denominan genes organizadores, se expresan no sólo en el sistema nervioso sino también en otros órganos y tejidos.

Los genes que dirigen la diferenciación específica de estructuras se llaman genes reguladores. No sólo rigen la estructura anatómica sino también la función de las células.

\section{Factores de crecimiento neuronal}

Diversas moléculas, creadas por secuencias de ADN, desempeñan un papel importante en la formación de dendritas y sinapsis, modulan la diferenciación neuronal y el camino que tienen que llevar los axones para encontrar su célula diana, son neurotransmisores, hormonas como la tiroxina, el cortisol, el péptido vasoactivo intestinal y otras proteinas como la neurotrofina-3, el factor de crecimiento neural, factor de crecimiento cerebral... 


\section{Estabilización sináptica}

A medida que aprendemos se produce una estabilización de las conexiones sinápticas y una especialización funcional. Según el modelo de estabilización sináptica específica, la actividad neuronal, influida por la acción de influjos epigenéticos y por su especificidad, es el mecanismo que estabiliza las sinapsis lábiles, las protege de la eliminación tras cada fase de sobreproducción sináptica. Los factores de crecimiento cerebral influyen en este proceso, estos factores son a su vez controlados por los sistemas neurotransmisores específicos y por los genes reguladores. El modelo de estabilización sináptica propone que los genes controlan las olas de sobreproducción sináptica no específica y los factores epigenéticos controlan el remodelado final.

\section{Periodos críticos}

Se cree que existen unos periodos en la proliferación y especialización de las neuronas en que los factores epigenéticos influyen sobre la configuración estructural del sistema nervioso.

\section{Referencias Bibliográficas}

ANDERSON, D. J. (1995) A molecular switch for the neuron-glia developmental decision. Neuron, 15, 1219-22

BENES, F. M. (1994). Development of the corticolimbic system. En Dawson y Fisher eds. Human Behavior and the developing brain, pp 176-206. New York: Guilford Press.

BERGADO-ROSADO, J. A.; Almaguer-Melian, W. (2000) Mecanismos celulares de la neuroplasticidad. Rev Neurol, 31 (11), 1074-1095

BREZUN, J. M.; DASZUTA, A. (1999) Deplection in serotonin decreases neurogenesis in the dentate gyrus ande the subventricular zone of adult rats. Neuroscience, 89, 999-1002

COWAN, W. M.; FAWCETT, J. W.; O'LIARY, D. M. (1984) Regresive events in neurogenesis. Science 225,1258-65.

COWAN, W. M. (1987) Organización del cerebro. Investigación y Ciencia, 68- 82.

DOBBING J., SANDS J. (1973) Quantitative growth and development of human brain

Arch Dis Child, 48, 757-767

FORTINI, M. E.; ARTAVANIS, S. (1993) Notch: neurogenesis is only part of the picture. Cell 75, 1245-7

FOSSE, V. M,; HEGGELUND, P.; FONNUM, F. (1989) Postnatal development of glutaminergic, GABAergic and cholinergic neurotransmiter phenotipes in the visual córtex, lateral geniculate nucleus, pulvinar and superior colliculus in cats. Journal of Neuroscience, 9, 426-435

GILLES, F. H.; SHANKLE, W.; DOOLING, E. C. (1983) Myelinated tracts: growth patterns. En Gilles F. H, Leviton A. and Dooling E. C. (eds.). The developing Human Brain: Growth and Epidemiological Neuropatology pp: 117-183. Boston : John Wright. 
HUTTENLOCHER, P. R. (1990) Morphometric study of human cerebral córtex development. Neuropsychologia, 28, 517-527.

HUTTENLOCHER, P. R. (1994) Synaptogenesis, synapse elimination, and neural plasticity in human cerebral córtex. En CA Nelson (ed), Trends to optimal development: the Minnesota Symposia on Child Psychology, vol 27, pp. 35-54

JANOWSKY, J. S. (1986) The outcome of perinatal brin damage:the role of normal neuron loss and axon retraction Developmental Medicine and Child Neurology, 28:375-89

JOHNSON, M. H. (1997) Developmental Cognitive Neuroscience. Massachusets. Blackwell.

JOHNSTON, M. V. (1988) Evidence for cholinergic projection to neocórtex from neurons in basal ganglia forebrain. Proceedings of the National Academy of Sciences of the USA, 76: 5392-6

KILLACKEY, H. P. (1990) Neocortical expansion: an attempt toward relating phylogeny and ontogeny Journal of Neuroscience, 2: 1-17

LANGMAN, A. (1969) Embriología médica. Madrid: Interamericana

MARÍN PADILLA, M. (1991) Embryology and pathology of the axial skeleton and neural dysrafic disorders Can J Neurol Science, 18:153-69

MARÍN PADILLA, M. (1992) Ontogenes of the pyramidal cell of the mammalian neocórtex and developmental cytoarchitecture: A unifying theory J Comp Neurol 321: $223-240$

MARÍN PADILLA, M. (1998) Cajal Retzius cell and the development of the neocórtex. TINS, 21: 64-71.

MARÍN PADILLA, M. (2000) Desarrollo, vascularización, neuroglía y citoarquitectura del cerebro humano Rev. Neurol. Cli,n., 1: 1-19

MOLNAR, Z.; BLAKEMORE, C. (1991) Lack of regional specificity for connections formed between thalamus and córtex in co-culture. Natur,e 351: 475-477.

OGAWA, M. et al. (1995) The reeler gene -associated antigen on Cajal Retzius neurons is a crucial molecule for laminar organization of cortical neurons Neuro, $n$ 14:899-912

O'LEARY, D. D. M. (1989) Do cortical areas emerge from a protocórtex? Tredns in neuroscience, 12:400-406.

O'LEARY, D. D. M.; Stanfield BB. (1989) Selective elimination of axons extended by developing cortical neurons is dependen on regional locale experiments utilizing fetal cortical transplants. Journal of neuroscience, 9: 2230-46.

PALMER, T. D.; TAKAHASHI, J., GAGE, F. H. (1997) The adult rat hippocampus contains primordial neural stem cells. Cell Neuroscence, 8:389-404

RAKIC, P., SINGER, W. (1988) Neurobiology of the neocórtex John Wyley and Son.: Berlin.

DEL RÍO, J. A. et al. A role of Cajal-Retzius cells and reelin in the development of hippocampal connections Nature 385:70-74 
RUBINSTEIN, J. L. R. BEACHY, P. A. (1998) Patterning of embryonic forebrain Curr Opin Neurobiol 8:18-26

SARNAT, H. B. (1992) Cerebral dysgenesis. Embriology and clinical expression Oxford: University Press. New York

SARNAT, H. B. (1998) Cómo construir un tubo neural: la genética molecular del desarrollo neuroembriológico Rev Neurol, 28 (161) : 110-116

SPEMANN, H. MANGOLD H. (1924) Uber induktion von Embryonalanlagen durch Implantaction Wilhem Roux Arch Entwick, 100:599-638

STEIN, S. KESSEL, M. (1995) A homeobox gene involved in node, notocord and neural plate formation of chick embryos Med Dev 49:37-48

VOLPE, J. J. (1980) Desarrollo normal y anormal del cerebro humano. Clin. Ped. NorthAm. Saunders: Philadelphia.

YAKOVLEV, P. I., LECOURS, A. (1967) The myelogenetic cycles of regional maturation of the brain. En A. Minkowski ed. Regional Development of the Human Brain in Early Life. Philadelphia: Davis. 